\title{
Dissemination and Preservation of Indigenous Medical Knowledge: A study Based on Special Secret Method of Communication of Vedageta (Medicinal Puzzles) Used in the Field of Indigenous Medicine in Sri Lanka
}

\author{
C. K. Gamage, PhD. ${ }^{1}$
}

\begin{abstract}
Sri Lanka is inherited with its own remarkable indigenous knowledge system as evident by its impact on the earlier inhabitants. This knowledge has its own evolution process, improvement and development within its cultural environment and transmission from generation to generation. During the recent past, there had been much dialogue on the use of indigenous knowledge as a solution to complex issues our society is confronted with. There is an increasing trend of attempting to use science and technology together with traditional knowledge to find mutually beneficial results such as best practices, which could be adopted in development projects. The management of indigenous knowledge will revalidate the past and dying cultures and promote community-based involvement in development programmes of the country. This study focuses on one of the secret knowledge transmission methods used in the field of indigenous medicine, "Vedageta". It is very clear that we thus address the need for paying great attention to this section of Indigenous Knowledge (IK) and as academics, librarians, policy makers, and planners should pay greater attention to this invaluable treasure of knowledge that is threatened by extinction. This research is based on survey method including literature survey and field survey. The books written on indigenous medicine were used as sources of literature survey. Distinguish 60 Ayurveda and Indigenous medical practitioners in Anuradhapura and Colombo districts were consulted for the field survey. Both types of data qualitative and quantitative were collected in the above stated manner and analyzed quantitative data by using the SPSS and also qualitative data is according to the descriptive manner. The study highlights relevance of Vedageta which is a traditional method of transferring indigenous medical knowledge among indigenous medical practitioners still remains intact.
\end{abstract}

Keywords: Dissemination of Knowledge, Indigenous Knowledge, Indigenous Medicine, Preservation of Knowledge, Vedageta,

\footnotetext{
${ }^{1}$ Senior Assistant Librarian, Institute of Indigenous Medicine, University of Colombo, Rajagiriya. E-mail: ckgamage31@gmail.com 


\section{Introduction}

\section{Indigenous Knowledge and its Significance}

In a very broad manner, knowledge can be divided into two major categories, Indigenous knowledge and Legitimized or Scientific knowledge. Indigenous or traditional knowledge is the knowledge that is unique to a given geographical location, society or a culture. It is also known as local knowledge, traditional knowledge, folk knowledge, civilization knowledge or traditional wisdom. Indigenous knowledge systems (IKS) which are also named Local knowledge systems (LKS) Traditional ecological knowledge (TEK) and Indigenous technical knowledge (ITK) represent experience acquired over several millennia of direct human contact with the environment.

From the beginning of mankind, every civilization has developed its own knowledge systems. These knowledge systems have been linked with their culture, languages, health care, food technology, education, environmental conservation and deal with their whole patterns of lives. This knowledge formulated by indigenous people or aboriginal tribes has been handed down from generation to generation for hundreds and thousands of years by word of mouth. Cultural rituals, and has been the basis for agriculture, water technology, food preparation and conservation, health care, education, and the wide range of other activities that sustain a society and its environment in many parts of the world for many centuries.

Inhabitants in Sri Lanka throughout its long history have produced a wealth of local knowledge and used it effectively for the human and socio-economic development of the country. It is a valuable asset for any country as it plays a vital role in making the nation more progressive and transforming its society. The quality and quantity of indigenous knowledge varies among community members, depending upon gender, age, social status, intellectual capability and occupation.

Indigenous Knowledge (IK) has emerged from the context of cultures and it fits into the society and also indicates the richness of the knowledge of indigenous people. It can be measured according to the measurements of the same culture itself. Otherwise it is difficult to measure a culture by using a measurement of other cultures, (Jayathilaka, 2009).

IK has no universally recognized definition and it is interchangeable or unique to a given culture or society. But despite the existence of such disparities there seems to be certain acceptable definitions given by some scholars.

"Traditional knowledge is the totality of all knowledge and practices, whether explicit or implicit, which is used in the management of social- economic and ecological facets of life." (Mugabe, 1999) 
"Indigenous knowledge is the sum of experiences and knowledge of a given ethnic group that forms the basis for decision making in the face of familiar problem solving. It is a mixture of knowledge created endogenously within the society and from outside, but then integrated within the society; and this knowledge is continuously changing and has an inherent capacity for absorbing relevant new knowledge form outside" (Lugeya, 1994).

Ranasinghe (2006) highlights the value of Indigenous knowledge as "one cannot reject all practices of indigenous knowledge on the ground that they are not laboratory tested. By experience people know indigenous knowledge practices relating to the testing methods of modern science may not sufficient to understand the principles behind indigenous knowledge practices."

Indigenous knowledge refers to the unique, traditional, local knowledge existing within and developed around the specific conditions of women and men indigenous to a particular geographic area (Grenier, 1998).

\section{Significance of Indigenous Knowledge in Sri Lanka}

Archeological evidences and some literary records show that Sri Lanka had been inhabited long before the arrival of Aryans, these early inhabitants or tribal groups who lived in the pre historic times had sufficient knowledge about manufacture of steel and iron implements, agriculture, irrigation \& water management, medicine, food technology and arts and crafts etc. It is alleged that pre historic King, Ravana had knowledge of medicine, incantations and all arts available prevalent those days. Tradition believes that he was the first to journey through air by a plane. These points to the essence of knowledge our pre historic community had.

Even today, Vedda community, the original inhabitants in Sri Lanka practices their own knowledge in their day to day activities. As well as they have existed in harmony with the environment for centuries. It is important to examine the strategies adopted by traditional tribes to maintain the balance of nature whilst fulfilling their needs.

The indigenous knowledge represents a body of knowledge relating to almost every facet of human life including Agriculture, Irrigation and water management, food technology, Health care, folklore, rituals and arts \& crafts etc. The earliest system of medicine that originated and maintained by people who lived in Sri Lanka before the advent of Āyurveda, was indigenous medicine. According to various legends and literary sources some of the terms like Hela vedakama or traditional system of medicine or folk medical system or Goda vedakama or Desheeya vedakama used by people in Sri Lanka to refer to the indigenous system of medicine. This system was handed down from generation to generation, and has a long tradition. Sri Lanka's history is full of achievements of kings who contributed to the development of field of medicine. Dutha Lakshana, Vedageta, Incantations and Kem system are several sub fields related to indigenous knowledge and these sub fields are widely used in the field of indigenous medicine in Sri Lanka. 
Dutha Lakshana is one of the special methods of communication prevalent in indigenous medicine is the ability to foretell the sickness (often a snake bite) from the gait of walking, posture etc. of the massager who comes to the physician for consultation. The method is equal to that of body language, but it is indeed almost unbelievable that the physician could name beforehand even the kind of snake - cobra or viper etc. that is involved. Vedageta (Medicinal puzzle) is also a special category of verses, written in Sinhala, in indigenous medical literature. Indigenous medical practitioners use this secret method of communication to convey indigenous medical knowledge inherited by them to their next medical generations or to whom so ever they wish. Kem is an esoteric method and it denotes protection, relief, method, and nap. The most important thing about the kem system is that it is widely used in the indigenous system of medicine. This abstruse Kem system has been used within the Sri Lankan indigenous system of medicine as a secret method of treating illness. Kem system includes incantations, rituals, beliefs and treatment within it. This system is prevalent in Asian as well as European countries. Our ancestors had their own method for curing ailments and they used incantations and perform thovil or devil dancing for that purpose. These four types of special knowledge i.e. Dutha Lakshana, Vedageta, Kem and rituals are also included under the umbrella of indigenous knowledge.

\section{Characteristics of Indigenous Knowledge}

Indigenous Knowledge is a virtue common to almost all the countries of the world. It differs from one another mainly depending on the historical and geographical factors pertaining to the countries concerned. Yet following features can be identified as essential characteristics out of this entity.

Every society and culture on earth has its own system of IK pertaining to each and every part connected to their lives. Hence IK builds among the people. These societies and cultures are geographically demarcated. This knowledge is not methodical and not laboratory tested i.e. not scientific and it was built by the people on their own, by practical knowledge. Most of the societies depend on this knowledge to a great extent to solve their problems of various kinds. The solutions to problems are very often and not questioned or challenged.

Evan at present, most of the societies in various countries in the world traditional decisions and actions are taken to solve everyday problems and IK helps to take basic decisions of relevant society. IK is handed over from generation to generation through oral instructions and word of mouth. In some times exemplary actions. This knowledge is based on ensuring security of their own culture, behaviors and the perpetuation of its own kind. Therefore, IK is more humane and it is based on kindness and compassion. Environmental friendliness is one of the major characteristics of IK and it does not believe in causing any harm to the environment in which the particular society lives. It is always well adjusted with the environment and it is best to protect environment. 
IK is not based on consumerism and is not profit driven. It is not used to exploit nature and derive profit from it. It never advocates destruction of forests or selling or killing animals to earn money. Evan archaeological treasures are protected for their value. IK is used practically for a preservation of the society and prevention of its decline or destruction. It is not fully explored yet and more research needs to be done.

\section{Purpose of the Study}

The early inhabitants who lived in Sri Lanka used their own knowledge systems. According to historical evidence, the people who lived in Sri Lanka had their own customs, ethics and traditions. Indigenous medical knowledge is one of the main components of the indigenous knowledge system. In short, the Vedageta remains a technique for the transmission of knowledge in indigenous medicine and this technique unlike others is being neglected in communication system and as well as not well known to the general public. The professionals in this field safeguard their knowledge secretly and in seclusion in order to handover their knowledge to their own families. There is a great likelihood of this method of knowledge vanishing with the disappearance of the Indigenous medical practitioners who used it. Even if this method is not used it is adequate evidence of the existence of valuable cultural aspects. Therefore, it is requisite that we should maintain and preserve this knowledge transmission technique for the future generation and also steps should be taken to make aware of them.

\section{Research Objectives}

1. To investigate the importance of Vedageta as a secret method of knowledge transmission used in the field of indigenous medicine in Sri Lanka.

2. To explore the importance of Vedageta to the general public.

3. To evaluate preservational value of Vedageta from being extinguished for posterity

\section{Methodology}

This research was based on survey method, which included literature survey and field survey. The sources consulted consist of indigenous medicine and also related literature of indigenous knowledge. The information gathered from these sources was used as secondary data. Field survey was the most important source, which provided primary data for this study. Colombo district in Western province and Anuradhapura district in North Central Province were selected as the study areas of this research. The relevant data and information were directly collected from the field survey by using the interview method. A separate questionnaire including open ended, close ended and multiple choice questions was developed for that purpose. Using purposive sampling method there were thirty medical practitioners from one district and altogether sixty from two districts of Colombo and Anuradhapura were interviewed. Both types of data qualitative and quantitative were collected in the above stated 
manner and analyzed quantitative data by using the SPSS and also qualitative data in the descriptive method.

\section{Results and Discussion}

\section{Results}

\section{Vedageta, a Secret Method of Communication}

Vedageta is one of the special secret methods of communication used in the field of indigenous medicine. In Sinhala literature also there are various types of verses. Among them, Vedageta introduces as special category of verses, written in Sinhala. 'Veda' means medical or of the physician 'Geta' is a puzzle to be unrevealed. It means therefore a puzzle to be unrevealed, offered in verses that could be remembered easily. Vedageta are verses, which are especially prevalent in the indigenous medical sphere. Traditional medical practitioners use this secret method of communication to convey indigenous medical knowledge inherited by them to their next medical generations or to whom so ever they wish.

Vedageta is included in the category of puzzles in Sinhala literature. According to Balalla (2003) considering the language used in these two categories of verses the ordinary puzzles as well as vedageta, it is concluded that they were written in the Kotte period or after that. These verses are mostly designed on the basis of personal experiences. Therefore, it is thought that one practitioner has a very limited number of vedagetas which were designed by himself or his own medical generation.

According to that this special kind of verses can be introduced as a secret method. It prevents the secret becoming common knowledge. This special method of communication used within one medical generation in its own way, differs from the others. However, indigenous medical practitioners designed these vedagetas by using the prescriptions given by their own medical generations during a long period of time.

It is a special kind of verses which gives a dual meaning, as in a puzzle. It gives an idea which is completely different from the apparent meaning. Among these vedagetas a large number is related to the field of snake bites.

There are several common factors which can be seen in vedageta. The major aim of these verses is to prescribe a decoction or any other treatment. For that purpose, they used secret words or words with dual meanings. Most of the verses use the words and the language common to rural and village societies. Another fact is that the words used for filling the gaps of verses increase the nature of the puzzle. And also, knowledge of language alone is not enough to write Vedageta (medical puzzles) created in order to describe a drug, decoction or a total prescription. For this in addition to the knowledge of language a person must have an academic knowledge of writing poetry. 


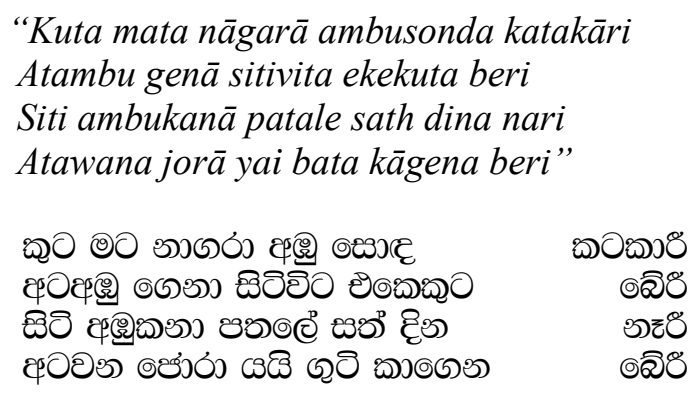

(Chandra, 1984)

This vedagetaya explains a decoction for typhoid fever. It consists of the ingredients Kuta (Kottan; Saussurea Lappa), Mata (Rasakinda; Tinospora Cordifolia (willd) Miers), Nāgarā ( Inguru; Zingiber Officinale Rose), Ambusonda (Kalānduru; Cyperus Rotundus Linn) and Katakāri (Katukarosana; Picrorhiza Kurroa Royle Ex Benth). Two 'kalans' and eight 'manchādi' of each kind is put into a pot to which eight cups of water is added and then boiled down to one cup. Powder of tippili (Piper Longum Linn), Ayurveda Pharmacopoeia, (1994) and rock salt is added in minute quantities to this before use. But its literally meaning is totally different from the above idea. It's a jovial story of a man named Joranis. He is a shrewd man who married eight women. Finally, was attacked by the eighth and had a narrow escape.

Here is another vedageta.

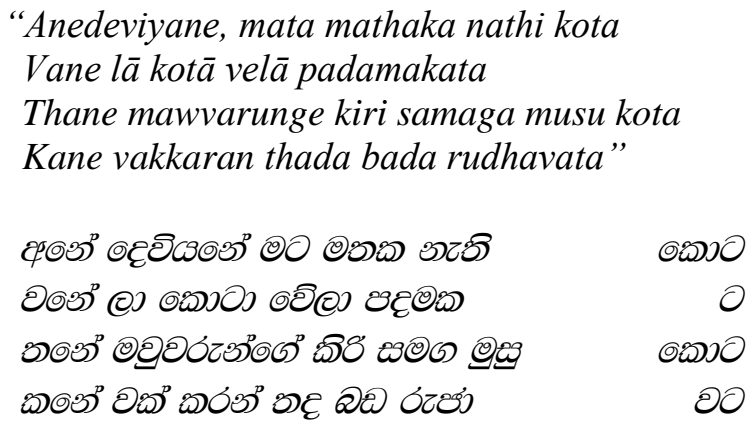

(Kusumarathna, 2005)

Traditional medical practitioners in Sri Lanka, used this decoction for severe stomachaches. It is very popular among them. But the meaning of this poem is not expressed clearly and people cannot understand it at once. Here, the word 'velā' represents the medicinal plant called velā. (Gynandropsis Pentaphylla)(Ayurveda Pharmacopoeia, 1994). But, one can may ask the question whether it means to be pounded or what is to be dried. How can one take the juice if it is to be dried? 'Vela' carries the double meaning 'leaf' and 'dried'. The real meaning of this poem is this; pound Gymanandropsis pentaphylla (vela), mix the juice with breast milk and pour the mixture into the ear for severe abdominal colic. But its literary meaning is "Oh 
god! I have forgotten. Pound vela in a mortar. Mix the juice with human milk and pour into the ear for a severe stomachache (colic) (Kusumaratna, 2005).

\begin{tabular}{|c|c|}
\hline & 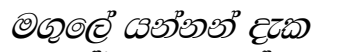 \\
\hline Kumbure mada kalal kalā & 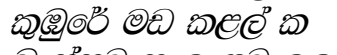 \\
\hline Vessata pela yata indala & 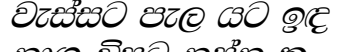 \\
\hline Nāga visata naśna kalā', & 3 \\
\hline
\end{tabular}

(Sithiyam sahitha Purana Sarpa Veda Potha, 1962)

This vedagetaya explains a treatment for removing the cobra toxin. Those who hear the puzzle will see in their imagination another word picture. This literally means; seeing the people going for a wedding, the mud of the field was leveled. For protection against the rain, having been in the hut, for the cobra toxin the medicine was administered through the nose. But the puzzle has other meanings as follows; 'mangule yannan' (seeds of mangul karanda; Pongeniya Pinnata), (Ayurveda Pharmacopoeia, 1994) 'kumbure mada kalal kala' (the core of kumburu seeds) and 'vessata pela yata indala' means the idea of human urine. According to that grind the core of both seeds mentioned above in human urine sieve it through a piece of clean cloth and blow the drops into the nose is a very effective treatment for the cobra toxin.

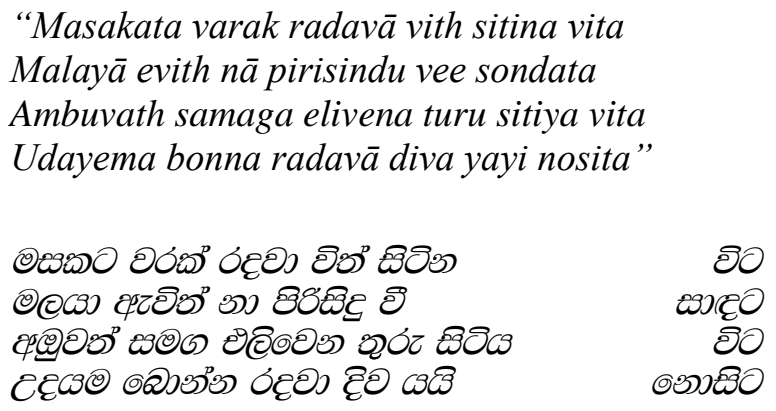

This poem on the topic of menstruation and the pains caused thereby. Unraveled it means take a handful of Malaya (Coriandrum Saivum Linn) (Ayurveda Pharmacopoeia, 1994) wash it and soak it in Amba (water) for a whole night, and the following morning give that water to drink. Thereby the pains will disappear. It is a wonderful way of saying what treatment to give. It is easy to remember in the form of a poem than a formula. This cannot be understood by an ordinary person. But it interpreted correctly by these of the particular indigenous medical tradition.

Tharuna liyan soyamin gena ge

Hossa tikak padā aragan

Bayak ethiva sookiri dāpan

Hossa vasā elavāpan re thulata

langata

katata

dorata 


\begin{tabular}{|c|c|}
\hline Re thisse pini beva tha & liya \\
\hline Udahenekke geta gena kata & aravapiya \\
\hline Hondata solavamin nopitata & haravapiya \\
\hline Katata kata thabā honda heti & uravapiya \\
\hline 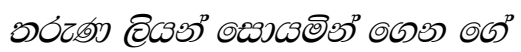 & 2e0 200 \\
\hline 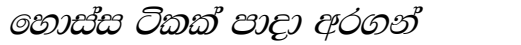 & $e(5)$ \\
\hline 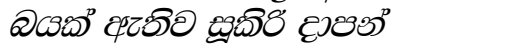 & 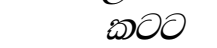 \\
\hline 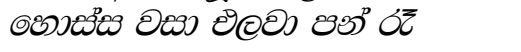 & बढ्रगठ0 \\
\hline 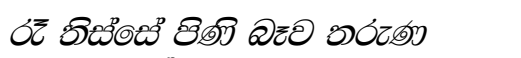 & \\
\hline Cद्s & be \\
\hline (6) & 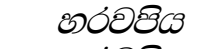 \\
\hline ஜூర & 8 \\
\hline
\end{tabular}

(Sirisena, 2003)

Tharuna liyan or young girls means tender king coconut or ordinary tender coconut. Hossa tikak padā (remove the top of the fruit) Sookiri dāpan katata (add candy an amount of six kalans) Six kalans of gall and powering them. Hossa vasa elavapan re dorata (close the opening leave the whole fruit with mixture open to the due night.) Take it in the morning, shake the mixture well and drink. (Re thisse pini beva tharuna liya - Udahenekke geta gena kata aravapiya - Hondata solavamin nopitata haravapiya - Katata kata thabā honda heti uravapiya) It is an excellent purgative. That is what the above puzzle says.

\begin{tabular}{|c|c|}
\hline Il masa pasukara beyata & ganne \\
\hline Ul kara leeye mul ara & ganne \\
\hline Beta dee gath thel ekkara & ganne \\
\hline Nāga visata meya nasna & anne \\
\hline 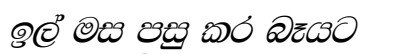 & \\
\hline 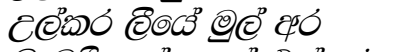 & の3 \\
\hline 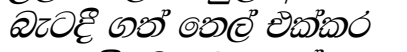 & \\
\hline $3 x$ & వు \\
\hline
\end{tabular}

(Sithiyam sahitha Purana Sarpa Veda Potha, 1962)

Il masa pasukara (After the month comes to the month of $I l$ is Uduvap) Uduvap means Udu (Phaseolus Mungo Linn) Beya (half or haves of the seed), Ul kara leeye mul (roots of kela (Butea Monosperma Kuntze), (Ayurveda Pharmacopoeia, 1994) Beta dee gath thel (ghee). Make the preparation in ghee and blow the sieved drops onto the nose. It is a cure for cobra poison.

$\begin{array}{lc}\text { Lajjāwathie nidiyannta hari } & \text { soori } \\ \text { kapā kotā ambarā ganu atha } & \text { nari } \\ \text { kepi keti vegirena muth le } & \text { sāri } \\ \text { bendi pamaninma suwa ve danu seka } & \text { neri }\end{array}$


(Sirisena, 2003)

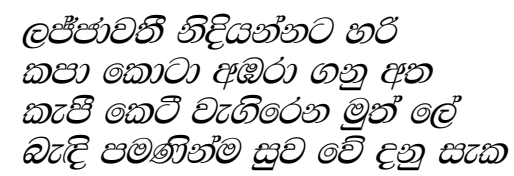

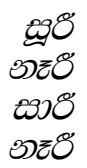

$3) \approx 8$

Lajjāwathie (The shy girl; Nidikumbā (Mimosa Pudica Linn) (Ayurveda Pharmacopoeia, 1994) nidiyannta hari soori (clever to sleep). Take the whole plant including the roots and grind it in the mixture to any bleeding wound. The bleeding will stop. It is a sure home remedy.

\section{Discussion}

Vedageta, as a Communication Method of Indigenous Medical Knowledge

During the discussion held with the 60 Ayurvedic and indigenous medical practitioners in Anuradhapura and Colombo district were asked to describe the techniques they used to transmit their knowledge to the next generation? According to the responses given by the 60 medical practitioners, it appears 10 major techniques have been used by them for that purpose. These ten (10), include not only knowledge transmission techniques used by general public in common but also unique and limited transmission techniques used only in the fields of Âyurvedic and indigenous medicine. These ten knowledge transmission techniques are shown in the following figure 1 .

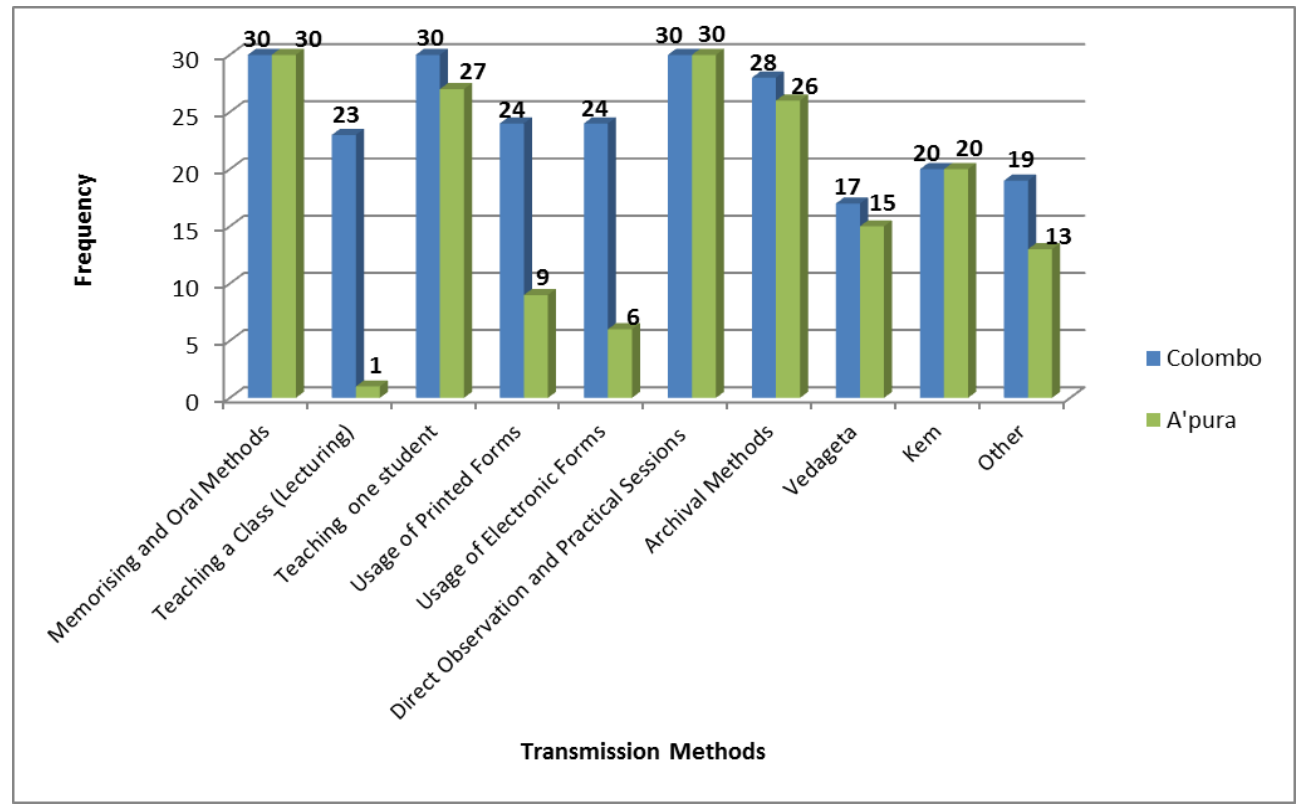

Figure 1 - knowledge transmission methods used by practitioners in Anuradhapura \& Colombo districts 
As evident from above graph memorizing and oral methods, direct observation and practical sessions are the most heavily used two types of methods not only to transmit the Āyurvedic and indigenous medical knowledge but also to obtain relevant medical knowledge and expertise, by the practitioners of two districts. Almost all practitioners in Colombo district, 60 out of 60 (100\%) use above two methods and same preference goes to the method of Teaching one student. The second priority of practitioners in Colombo district goes to the usage of archival methods like Ola leaf manuscripts and hand written manuscripts. It reaches $93.33 \%$. Teaching one student is the second preferred method used by the practitioners of Anuradhapura district. $(90.00 \%)$ Usage of modern communication techniques such as printed forms and electronic methods by the practitioners in both districts to transmit Ayurvedic and Indigenous medical knowledge is significantly different. Practitioners in Colombo district; 24 practitioners out of 30, make use of printed and electronic media. It is $80.00 \%$. Compared with the above values in Colombo district, only a meager percentage of about 9 and 6 practitioners in Anuradhapura district use the above two methods. Evan though Vedageta and Kem are esoteric, some physicians use them for the transmission of knowledge. For instance, in Colombo district out of 30 practitioners 17 use Vedageta and 20 make use of Kems. (56.67\% and 66.67\%) In the district of Anuradhapura the number of practitioners used these two transmission methods are 15 and 20 respectively. They reach $50.00 \%$ and $66.67 \%$. It indicates the idea that there is no difference between the two districts by usage of these two methods of Vedageta and Kem. It demonstrates and emphasizes the importance accorded to these traditional methods even at present.

\section{Summary of Findings}

- There is not much difference between the two districts by usage of this method of Vedageta,

- The study demonstrates the importance accorded to this traditional method of communication even at present.

- There is a great risk of this valuable method of transmission an aspect of indigenous medicine disappearing from our culture within few decades.

\section{Conclusion}

Vedageta which is a very special secrete method of communication used in the field of Āyurveda and indigenous medicine, process by small esoteric groups. There is a danger of this knowledge completely getting out of fuse with the demise of native physicians who own this medical knowledge currently. Therefore, it is a national responsibility to protect and preserve this valuable national heritage for future generation. In this regard the duty of librarians, relevant government authorities and policy makers are taking necessary steps to preserve that invaluable medical knowledge is a timely need. 


\section{Recommendations}

It is a very important and timely need to collect, record and develop indigenous knowledge for the benefit of future generations. Preservation of indigenous medical knowledge is especially important for social and cultural reasons. Most of the time, indigenous knowledge is preserved through various family histories, taboos, symbols, myths, legends, rituals, dances, festivals, proverbs, poetry, literature and role play, folklore and other systems. Some suggestions for the preservation and development of indigenous medical knowledge in Sri Lanka, especially esoteric methods like Vedageta are as follows.

Establishment of an institution under the government patronage to collect, record, organize, interpret, preserve and disseminate indigenous medical knowledge

To make society especially the knowledge workers such as librarians and other academics aware of the importance of collection and preservation of this type of indigenous medical knowledge.

A special subject designated as indigenous knowledge system including Āyurveda and indigenous medical systems, should be included in the school health curriculum for classes from 6th from up to G.C.E.(Ordinary Level).

Use of modern technology to harvest, preserve, store and disseminate indigenous medical knowledge

Provision of facilities for research in the field and to get the indigenous medical knowledge patented whenever possible are some of them.

Taking appropriate steps to prevent and disappearance of indigenous/ traditional medical knowledge and the transmission of such knowledge to future generations by appointing appropriate Local Bodies to deal with the problem.

Holding island wide seminars, lectures, workshops regularly and at definite times annually for the benefit of physicians of both categories, thereby updating their knowledge and re-orienting them as necessary.

Preservation of all esoteric methods including Incantations, Vedageta (medical puzzles), interpretation of messenger's behaviour and body language (Dutha Lakshana) and Kems used by the traditional physicians with State intervention.

Establishment of an effective State mechanism to improve and promote Āyurveda and indigenous medical research and propagation of knowledge. 


\section{References}

Ayurveda Pharmacopoeia. Volume I, Part Two, $2^{\text {nd }}$ ed. (1994). Colombo:Department of Ayurveda.

Balalla, N. B. P. (2003). Vedageta Pilibanda Vimarshanathmaka Addhayanayak. $\mathrm{PhD}$ Thesis, Kelaniya: University of Kelaniya.

Chandra, R. S. (1984). Sara Sankshepaya. ed. Aryadasa Kumarasinghe. Colombo: Department of Ayurveda.

Grenier, L. (1998). Working with Indigenous Knowledge: A guide for researchers. Canada: International Development Research Centre.

Jayathilaka, Y. D. (2009). An Anthropological Study of Indigenous Knowledge with Special Reference to Vedda Communities of Dambana and Henanigala. Journal of Social Sciences, 01(2), 251-261.

Kusumarathna, S. (2005). Indigenous Medicine in Sri Lanka: A Sociological Analysis. Nugegoda: Sarasavi Publishers.

Katru nama sadikari lekanaya (Sinhala) (2005). Colombo: National Library and Documentation Services Board

Lugeya, S. (1994). The Role of Farmer's Indigenous Knowledge in Natural Resources Management in Sokoin. Convocation Workshop, University of Agriculture.

Mugabe, J. (1999). International Property Protection and Traditional Knowledge; An international policy discourse. Biopolicy International, 21.

Ranasinghe, P. (2006). Indigenous Knowledge in Sri Lanka. Alumni Association of the Department of Library and Information Science, Vidyarthi, Kelaniaya: University of Kelaniya. $134-143$

Sirisena, M. R. (2003). Rahasya Aushadha Shathakaya hevath Vedageta Siyaya. Colombo: S. Godage

Sithiyam sahitha Purana Sarpa veda Potha: Part Two. (1962). ed. Matara Kamburupitiye Samarasinghe, Aluthgama: C. S. Mudannayaka. 